Metabolism in filamentous fungi

The Filamentous Fungi. Vol. 2: Biosynthesis and Metabolism. Edited by John E. Smith and David R. Berry. Pp. xiv +520. (Arnold: London, June 1976.) $£ 19.75$.

$\mathrm{MuCH}$ of the space allocated to this review could be taken up by listing the twenty-two authors and the seventeen chapters which they have contributed to this, the second volume of a series on the filamentous fungi. The writers endeavour to cover all aspects of biosynthesis of carbohydrates, lipids, fatty acids, nucleic acids and proteins and the associated pathways of intermediary metabolism and nutrient assimilation.

The authors, in their attempts to succeed in this, are forced to produce highly condensed articles some of which, although they may be comprehensive, are very hard work to read. Many authors, however, do set out to make their contributions readable and comprehensible to those not working directly in their own field. A. T. Bull and $\mathrm{M}$. E. Bushell begin by providing a good introduction to the problems encountered in the construction and operation of continuous flow fermenter systems for filamentous fungi.

A. H. Rose provides an excellent account of the clinical nature of membrane components. At the other end of the spectrum, one or two authors make few concessions to anyone who is not fully conversant with the terminology and techniques used in their discipline, and consequently have produced chapters which are very difficult to digest.

The latter is not consistent with the editors' intent to include undergraduate and postgraduate students in the readership. Although perhaps not all subjects would have been amenable to this treatment, it would have been useful if the editors had encouraged authors to begin their chapters with a brief introduction to the nomenclature. For example, the chapter on Carotenoids by T. W. Goodwin begins with a good introduction which rapidly accelerates to a detailed exposition with which the reader can keep in step.

An encouraging feature of this book is that a number of chapters conclude with suggestions for useful future developments, whereas volumes presenting up-to-date reviews often leave one with the feeling that most worthwhile work has been done or is in hand. V. W. Cochrane, in the closing paragraphs of his chapter on glycolysis, encourages workers in the field to investigate Neurospora crassa in the same detail with which bacteriologists have studied Escherichia coli and also points out that some groups of fungi have been largely neglected. In another instance, J. A. Pateman and J. R. Kinghorn have attempted to present their review of nitrogen metabolism in such a way as "to allow deeper study for those interested in a particular field"'.

This is a valuable volume as it provides a good review of present knowledge, with copious references, and it may well have the effect of encouraging others to investigate some of the neglected areas of the subject.

H. A. S. Epton

Dr Epton is a Lecturer in Botany at the University of Manchester, UK.

\section{Numerate account of marine ecology}

The Ecology of the Seas. Edited by D. H. Cushing and J. J. Walsh. Pp.x+ 467. (Blackwell: London and Oxford, 1976.) $£ 8.75$.

The names of Cushing, Dugdale, Kelley, Parsons, Steele and Walsh, to mention but 6 of the 14 contributors, should be sufficient to promise good value in this book for marine ecologists. I have no doubt that it is good value, and to be highly recommended.

What these very numerate ecologists aimed to do, under the leadership of Cushing and Walsh, was to set out "the present state of knowledge of the quantitative nature of marine ecosystems": in 6 parts, comprising 16 chapters, with very adequate references and indexes (authors, subjects, species and geographical). They proceed systematically from the characteristics of the seas and the life they maintain, through the forms and functions of marine ecosystems, with some of the consequences in terms of evolution, and of yield for man. The final section is in two parts: the first, an excellent chapter on sampling (by J. C. Kelley), and the second concerning a comprehensive "simulation model" of ecological relationships at three trophic levels, within the upwelling systems off Peru, Baya California and north-west Africa.

In all this, prime emphasis is on the processes concerned, both hydrodynamic and biological: indeed, life in the sea. In association there is emphasis on the absolute necessity for distinguishing between variability in space and variability in time, which variations have been "confounded" in more senses than one for most aspiring marine ecologists over the past 50 years.

I cannot but be impressed by the way in which so many of the problems -which could be seen only dimly 50 years ago and, although perhaps perceived a little more clearly 25 years ago, still left marine ecologists gravelled for lack of both data and technique-are now (following great developments in both) beginning to yield understanding, and even the possibility of prediction, in such complicated circumstances. That the methodology is far from simple, and the options many, is further illustrated by a quotation from the last chapter, by Walsh (references omitted): "Depending on the problem, one must decide whether steady state or time dependent studies with simulation and/or statistical models . . . involving the analytical or numerical solution ... of differential or difference equations . . . made of linear or non-linear terms ... should be solved on analog or digital computers . . . in relation to spatial or single point considerations . . . and exogenous or endogenous driving functions . . within a stochastic or deterministic parameter space ....".

As Cushing says in his preface, the contributors are writing as scientists, who have spent long periods at sea, for scientists who are beginning to work at sea. I find it difficult therefore, to think of a better or more challenging introduction. Whether this important science will, however, be able to expand in foreseeable circumstances, in the manner that progress made so far seems to justify, is uncertain to say the least. Quite apart from neverending arguments about the Law of the Sea, it is inherently very costly, if only in terms of ships and resources required for the extensive synoptic surveys that better understanding demands. For this reason alone, one of the most important points made by Walsh concerns the present challenge to devise new methods of exploiting existing data banks, rather than heedlessly adding to them!

One last point: taking into account the high price and unattractive binding, it is difficult to understand why the publishers let the team get away with duplicating Fig. 7.6 by the identical (except for the legend)
Fig. 8.2.
C. E. Lucas

Sir Cvril Lucas was formerly Director of the Marine Laboratorv, Aberdeen (retired 1970) and subsequently a member of the Natural Environment Research Council, $U K$. 